several years, much of it prompted by Professor Akito Arima, the newly elected president (see Nature 338, 8; 1989). Now, a committee under Professor Akiyoshi Wada, the physicist turned molecular biologist, has put forward a plan to reorganize the graduate school of the science faculty. The plan would transform the education of scientists at Tokyo, but that is only half of it. The true objective is to create a science faculty which is also an internationally connected research community. Wada, who becomes the dean of the graduate school on 1 April, will be well-placed, but success will hang on whether the Japanese government will endow the plan with resources - and turn a deaf ear to the grumbles there will be that Tokyo is seeking merely to perpetuate its present exalted status and to fight off moves by the national laboratories to run their own graduate programmes.

The oddest attribute of modern Japan is the ostentatiously un-modern condition of its universities. The curriculum is rigid; two years of general education, then two of specialized education (including some experience of working in a research laboratory), for every undergraduate. The structure of the faculty is similarly cast in concrete; the koza system attaches to each full professor $($ kyoju $)$, who is in himself an autonomous academic unit, a couple of more junior academics and a research assistant who may become, if that is the great man's inclination (there are few women professors), his intellectual skivvies. (However menial their function and however meagre their salaries, all these people have tenure.) There is also a portion of the university's disposable income to spend on research, usually so small that it would seem derisory even to Britain's pauperized academics. Even at the University of Tokyo, there are buildings so shabby, ill-equipped and dust-ridden that they seem hardly to have been touched since they were built, mostly in the rebuilding programme following the great earthquake and fire of 1923.

How, in these circumstances, can research flourish? That many Japanese academics have won glowing international reputations is a testament to the durability and ingenuity of the human spirit. In the Japanese system as it is, the pursuit of understanding is but foolish selfindulgence. Doing nothing is much easier, but the simplest way to a seemly academic life is for a kyoju to strike a few bargains with industrial companies, which will bring decent equipment, and to train graduate students on related applied research (ensuring that they also have comfortable jobs). Exceptional circumstances do arise, as when a bunch of physicists win approval (and funds for) a space programme, or when a government laboratory is sited on a university campus, but these merely show how moribund and inward-looking is the system as now constructed.

The new recipe for Tokyo's science faculty would change this from the bottom up. First, most undergraduates after the two years of general cducation would set out on a four- or five-year course leading to a research degree. A crucial element of the plan is that those concerned should work in basic research - which is where the rub lies. For the plan will succeed only if there are enough more senior people practising interesting research with whom students can rub shoulders. That argues for what has long been Japan's most urgent academic need, more positions at the postdoctoral level than the few hundred fellowships now administered by the Japan Society for the Promotion of Science. There will also need to be research funds.

In the long run, only the Ministry of Education can ensure that Tokyo's plan succeeds. Does it fully appreciate the importance of the venture? The declared objective is to make scholarship seem an honourable pursuit and to create an intellectual climate that will be attractive to people from overseas. (While all academic posts at the national universities are in principle open to foreigners, only a tiny proportion are thus occupied.) Japan does not have to swallow the complaint by US diplomats that the monoglot character of the national universities is proof of yet another restraint of trade to know that the richest country in the world should hang its head when even its grandest universities are such poor magnets for scholars from elsewhere.

\section{Convictions on ozone}

Mrs Margaret Thatcher's crusade in favour of the ozone layer should not blind her to greenhouse gases.

Now that the British Prime Minister's zeal is harnessed to the preservation of the ozone layer, the rest of us will be able to sleep more soundly when we sunbathe. That is one of the lessons to be drawn from the conference in London at the weekend (see page 101), when Mrs Thatcher recruited a further score of signatures for the Montreal Protocol which commits its signatories to a 50 per cent reduction of eight chemicals believed to affect the ozone layer. That is a considerable achievement for the persuasiveness of conviction, but there is a long way to go.

This journal's conviction is that the Montreal Protocol is chiefly to be valued because it is a precedent for the much more constraining convention there will have to be if ever it becomes necessary to restrict by international agreement the emission of carbon dioxide so as to avoid the now-familiar greenhouse effect. It is true that there are links between the Earth's climate and the concentration of chlorofluorocarbons in the atmosphere, but carbon dioxide will be the hard diplomatic nut to crack because it is the by-product of most economic activity. So why not start on that now, for fear of using up the goodwill of the world's environment ministers?

\section{"Endymion"}

Readers persuaded by last week's reference to Wordsworth's "Endymion" that Nature's name must have derived from Keats should know that the reference is to one of Wordsworth's "Miscellaneous sonnets", all of which are untitled. 